\title{
Caminando entre textos feministas autocensurados. Conferencia-performance de Concha Jerez. El Escorial 1-7-2013
}

\author{
Concha JEREZ \\ Artista y Profesora Asociada de la Facultad de Bellas Artes de la Universidad de Salamanca \\ conchajerez@gmail.com
}

Recibido: 15.09 .2013

Aceptado: 02.10.2013

\section{RESUMEN}

El texto expone las motivaciones y el desarrollo de la Conferencia-Performance "Caminando entre textos feministas autocensurados" que Concha Jerez presentó en el curso de verano de El Escorial Desde la creación a la representación. Las mujeres como profesionales del arte en el año 2013.

Palabras clave: Feminismo, Arte, Conferencia, Performance

\section{Walking with feminist self-censored texts \\ Conference-Performance by Concha Jerez \\ El Escorial 1-7-2013}

\begin{abstract}
The text presents the motivation and development of the Conference-Performance "Walking with feminist selfcensored texts" by Concha Jerez. The Conference-Performance was presented in the summer grade From creation to representation. The women of art in 2013 in El Escorial.
\end{abstract}

Key words: Feminism, Arte, Conference, Perfomance

\section{PRESENTACIÓN}

Al ser invitada a participar en el Curso de Verano Complutense 2013 integrado básicamente, como es lo habitual, por Conferencias y Mesas Redondas, decidí de acuerdo con las organizadoras, el darle a mi colaboración la estructura artística de Conferencia - Performance.

Como el título del curso era Desde la creación a la representación. las mujeres como profesionales del arte, propuse como título de mi Conferencia - Performance: Caminando entre textos feministas autocensurados. 
El tema de la Autocensura ha sido el origen conceptual de mi obra a partir de 1974 en los últimos estertores de la dictadura franquista. Posteriormente, en la transición hacia la democracia, seguí percibiendo la imposibilidad de poder decir todo lo que uno pensaba, ni en lo político, ni en lo social, ni en lo personal y en 1976 realicé mi primera Instalación en la Galería Propac de Madrid que llevaba como título La Autocensura.

Han pasado muchos años desde entonces hasta ahora -cuarenta años nada menosen los que he seguido comprobando la enorme vigencia de la Autocensura, cada vez mas soterrada pero no por ello menos real. Debido a ello, he tenido que seguir incluyéndola en mis obras presentándola con diversas formulaciones.

Al elegir el título de mi Conferencia-Performance para este curso, decidí incluir en él la idea de la Autocensura relacionada con posibles textos feministas autocensurados. El objetivo era alertar sobre el posible exceso de confianza en la cercanía de la consecución de normalización de los derechos de la mujer que, por el momento, sigue estando aún lejos de conseguirse en todos los aspectos de la vida cotidiana.

En mis performances he venido enfatizando desde sus contenidos en la idea de Performances In Situ. Ese es y ha sido uno de los intereses fundamentales que han movido el conjunto de mi obra desde los años setenta.

Esta performance tiene como estructura básica un vídeo -con sonido incorporadorealizado para la Instalación InterMedia que con el título 2.044 ESPACIOS DE 4' 33" presenté en el espacio de ESC en Graz como obra In Situ -dentro del Festival de Otoño de Stiria y del Musicprotokoll de dicha ciudad- en septiembre / octubre de 2010.

El vídeo, titulado CUATRO RECORRIDOS DE 4' 33" - en referencia a la obra de John Cage-, integra la acción mía de caminar recorriendo un espacio, con cuatro posibles contenidos autocensurados de mi conferencia In Situ, cada uno realizado en 4' 33" y que, como en la obra de Cage, absorven todos los sonidos que surgen en esos cuatro intervalos únicos e irrepetibles extendiéndose también, en este caso, a todo lo que sucede a nivel visual.

Al audio del vídeo le añadí para esta performance otro audio integrado por la grabación previa de 16 preguntas escritas y leídas por mi - repartidas en módulos de cuatro en cada uno de los recorridos- y que son las siguientes:

1 ¿Por qué, según datos de 2008-2009, de las 177 exposiciones individuales del Consorcio de Galerías de Arte Contemporáneo, sólo 34 fueron de artistas mujeres?

2 ¿Por qué de las 94 exposiciones individuales organizadas por el MNCARS, el MACBA y el IVAM entre 2005 y 2007, tan sólo 15 estuvieron dedicadas a artistas 
mujeres, es decir, el 16\%?

3 ¿Por qué entre 1999 y 2009, de 973 exposiciones individuales de artistas en 22 Centros de Arte Contemporáneo en España, solo el 9,4\% estuvieron dedicadas a artistas españolas?

4 ¿Por qué de las artistas representadas en las colecciones del MNCARS y del MACBA solo un 5\% son artistas españolas y de las obras que integran dichas colecciones sólo el $4 \%$ son de artistas españolas?

5 ¿Por qué en 2009, de un total de 21 miembros del Patronato del MNCARS, solo 5 eran mujeres? ¿Por qué de 13 miembros del Patronato del IVAM, solo 3 eran mujeres? ¿Por qué de 11 miembros del Patronato del Patio Herreriano solo 3 eran mujeres?

6 ¿Por qué de los tres suplementos culturales de diarios de ámbito nacional con mayor tirada en 2008, entre los 44 críticos de arte colaboradores había sólo 7 mujeres, es decir, el $16 \%$

7 ¿Por qué de los/as 12 artistas seleccionados/as para el pabellón español de la Bienal de Venecia en sus últimas seis ediciones solo hubo entre ellos/as 2 artistas mujeres?

8 ¿Por qué de las 43 exposiciones individuales organizadas entre 2002 y 2005 por la SEACEX, Sociedad Estatal para la Acción Cultural Exterior, sólo 2 fueron de artistas mujeres, es decir, un 5\%?

9 ¿Porqué de las 21 exposiciones individuales organizadas o patrocinadas por la SEACEX en 2007 y 2008, tan sólo 3 estuvieron dedicadas a artistas mujeres, es decir, un $14,3 \%$ ?

10 ¿Por qué en la Real Academia de Bellas Artes de San Fernando, hay 58 académicos, es decir, un $96,6 \%$ y solo 2 académicas, es decir, un $3,3 \%$ ?

11 ¿Por qué en 15 convocatorias del Premio Nacional de Fotografía solo se ha concedido el premio a 3 fotógrafas?

12 ¿Por qué en 16 convocatorias del Premio Nacional de Artes Visuales de la Generalitat de Catalunya solo se ha otorgado el premio a 2 artistas mujeres?

13 ¿Por qué en 15 convocatorias del Premio Nacional de Artes Plásticas solo se ha concedido el premio a 3 artistas mujeres?

14 ¿Por qué en 9 convocatorias del Premio Velázquez solo se ha otorgado el premio a 1 artista mujer? 
15 ¿Por qué en 28 convocatorias del Premio Príncipe de Asturias de las Artes no se ha otorgado nunca el premio a ninguna artista mujer?

16 ¿Porqué se producen las cifras anteriores en España si en 2.011 el 70\% de los Licenciados en Bellas Artes son mujeres y el 30\% son hombres?

Concluyo este breve texto con la secuencia de mi Conferencia- -Performance realizada el 1 de Julio de 2013 en el Aula 13 del Colegio Universitario María Cristina de El escorial dentro del curso DESDE LA CREACIÓN A LA REPRESENTACIÓNLAS MUJERES COMO PROFESIONALES DE LAS ARTES.

\section{SECUENCIA DE LA CONFERENCIA-PERFORMANCE}

Al comienzo, la performer se encontraba sentada en la mesa donde se desarrollaron las ponencias del Curso de Verano Complutense 2013 - Desde la creación a la representación. las mujeres como profesionales del arte-, como si fuese a impartir una conferencia.

Delante de ella tenía un rollo de papel vegetal con escritos ilegibles autocensurados.

1. Se iniciaba la performance con la puesta en marcha del vídeo cuatro intervalos de 4'33" mientras la performer se ponía en pié a la vez que cogía el rollo de papel vegetal con escritos autocensurados, manteniéndose en esa misma posición y lugar durante toda la performance.

2. A partir de ese momento y hasta casi la conclusión de la performance, la performer fue desenrollando el rollo de vegetal de veinte metros con textos autocensurados que era el contenido de la conferencia.

El movimiento de desenrollar era muy lento.

Desde la mesa el papel iba cayendo al suelo por delante de la misma. Progresivamente la performer iba subiendo lentamente el rollo de papel vegetal, de tal modo que su rostro iba desapareciendo tras él hasta ocultarse del todo, permaneciendo así hasta casi el final de la acción de desenrollar.

3. Después de escuchada la pregunta 16, la performer desencadenó una acción violenta de arrugar el papel en su totalidad hasta el final del vídeo, en cuyo momento tiró el resto del papel y se sentó detrás de la mesa como al principio.

Así concluía esta conferencia-performance. 